\title{
LAS FUNCIONES DISCURSIVAS DE QUE ESTO (Y) QUE LO OTRO Y SU VALOR INDETERMINADO. UN ESTUDIO EN DATOS DEL ESPAÑOL DE LA CIUDAD DE MÉXICO
}

\section{DISCOURSE FUNCTIONS OF QUE ESTO (Y) QUE LO OTRO AND ITS VALUE UNDETERMINED. A STUDY IN MEXICO CITY'S SPANISH}

\author{
Josaphat Enrique Guillén Escamilla \\ Universidad Nacional Autónoma de México. \\ jguillene@gmail.com
}

\begin{abstract}
Resumen:
A partir de datos del español de la Ciudad de México, el objetivo de esta investigación es describir las funciones de que esto (y) que lo otro como marcador discursivo y determinar si puede considerarse como un mecanismo del lenguaje vago o por aproximación (Channell; Vigara, Español). Los datos provienen de tres corpus de español de la Ciudad de México que, en conjunto, componen un total de 174 entrevistas. El análisis permitió identificar tres funciones: (i) enumeración indeterminada, (ii) cierre indeterminado de serie y (iii) sustituto de habla reportada. A partir de estos resultados, se concluye que que esto (y) que lo otro codifica valores pertenecientes al lenguaje vago, relacionados con la abreviación discursiva, la cortesía positiva y la atenuación asertiva, todo esto gracias al carácter indeterminado del marcador.
\end{abstract}

Palabras clave: marcadores discursivos, indeterminación, lingüística de corpus, lenguaje vago.

\begin{abstract}
:
Based on data from Spanish of Mexico City, the aim of this study is describing functions of que esto (y) que lo otro as discourse marker and figuring out if it can be considered as a mechanism of vague language or by approximation (Channell; Vigara, Español). Data comes from of three corpora of Spanish of Mexico City which, together, integrate a total of 174 interviews. According to analysis, this discourse marker has three functions: (i) indeterminate enumeration, (ii) indeterminate closure of series, and (iii) replacement of reported speech. Thus, we concluded that que esto (y) que lo otro encodes values which belong to vague language, these values are related with discursive abbreviation, positive politeness, and assertive mitigation, all this thanks to the indeterminate character of this marker.
\end{abstract}

Key words: discursive markers, approximation, corpus linguistics, vague language.

Recibido: 10 de agosto de 2021

Aceptado: 18 de noviembre de 2021 


\section{Introducción}

En los años recientes, el estudio de los marcadores discursivos ha experimentado un amplio desarrollo; de tal manera, actualmente contamos con varias descripciones detalladas que precisan sus rasgos formales y funcionales. En este escenario, algunos de estos estudios se han centrado en señalar la relación de ciertos marcadores discursivos -como y así, y tal, o cosas así, tipo, plan, entre otros- con el lenguaje vago (Channell; Fuentes, La aproximación; Borreguero) o la expresión de sentido por aproximación (Vigara, Español). Así, se han postulado términos como marcadores de (in)conclusión (Domínguez), marcadores de final de serie enumerativa (Cortés, Elementos. Perspectiva interactiva; Elementos. Perspectiva textual), apéndices generalizadores (Gille; Gille y Häggkvist), marcadores de habla aproximada (Fuentes, Diccionario), completadores de frase (Tusón) y apéndices de inconclusión (autor). Todas estas definiciones apelan al carácter vago que imprime este tipo de partículas al discurso, esto es, funcionan como difusores de significado. Precisamente, en esta investigación se busca abonar a la caracterización de estos marcadores a partir del análisis de que esto (y) que lo otro, en casos como (1) y (2):

(1) 322 I: pero yo mana quería verlo/ porque yo quería que me la registrara/// ¿sí?/ entonces por eso era que yo andaba ahí bien/ "y/ ¿vamos a registrar a la niña?"/ "sí/ déjame este/ traer papeles que esto que lo otro" "órale"/ porque como teníamos que ir los dos/ puesto que no estábamos casados (CSCM, entrevista 57).

(2) 836 I: y todavía me hablan muchos amigos/ ¿verdad? < veá> y/ gente que me conoce y me pide consejos así de "oye/ ¿qué hago con el camión?/ y que esto y que lo otro < lotro>" (CSCM, entrevista 50).

En breve, el primer objetivo de este trabajo es describir las funciones discursivas de que esto (y) que lo otro en datos del español de la Ciudad de México. El segundo es relacionar estas funciones con los valores que se desprenden de su carácter indeterminado, como difusor de significado. Para lograr estos objetivos, se revisaron tres corpus: (i) $E l$ habla de la ciudad de México. Materiales para su estudio (Lope Blanch), (ii) El habla popular de la ciudad de México. Materiales para su estudio (Lope Blanch) y (iii) Corpus Sociolingüístico de la Ciudad de México (Martín Butragueño y Lastra). Y, en el apartado 
teórico, se recurrió a las propuestas de Channell, Vigara (Español), Porroche, Pons, Aliaga e Iglesias, Loureda y González y Loureda, principalmente.

Por último, para su exposición, el resto del trabajo se encuentra organizado de la siguiente manera, en $\S 2$ se describen las particularidades del lenguaje vago, se justifica por qué consideramos que que esto (y) que lo otro es una expresión cuasi-lexicalizada y explicamos las funciones que puede desarrollar dentro del discurso. En $\S 3$ se detalla la metodología que seguimos para realizar nuestra investigación, mientras que en $\S 4$ se presenta el análisis de los datos. En $\S 5$, se discuten los resultados del análisis y en $\S 6$ se puntualizan las conclusiones.

\section{EI lenguaje vago y la expresión de sentido por aproximación}

De manera tradicional, la conversación coloquial, caracterizada por la ausencia de planificación, un fin comunicativo socializador y el tono informal (Briz, El español), ha sido juzgada como descuidada, imprecisa y pobre, principalmente porque se ha evaluado desde una perspectiva gramatical; además, la falta de planificación previa $-o$ la planificación sobre la marcha- también ha contribuido a esta caracterización (Briz, Los llamados; Vigara, Morfosintaxis). No obstante, desde hace varios años ya, algunos autores han señalado que estos aparentes descuidos e imprecisiones pueden cumplir funciones particulares durante la comunicación (Vigara, Morfosintaxis); más aún, han defendido la idea de que lo fundamental no es la falta de planeación, sino que la materia discursiva esté orientada "hacia una clara finalidad comunicativa" (Narbona y Morilo 109). En este escenario, y como se podría esperar, la oralidad coloquial promueve la aparición de ciertas estrategias que responden a las necesidades inmediatas que impone el intercambio comunicativo hic et nunc. De entre todas estas estrategias, aquí estamos interesados en describir la aproximación, es decir, una forma de expresar el sentido de forma vaga o imprecisa, pero que permite alcanzar un intercambio comunicativo exitoso (Vigara, Español).

En principio, conviene recordar que la conversación coloquial se caracteriza, entre otras cosas, por la inmediatez, por la interacción cara a cara y el conocimiento compartido entre los hablantes. Así, se presenta como un intercambio más cercano al polo de la lengua 
de proximidad, donde hay menor distancia en el espacio y tiempo, mayor privacidad en la comunicación, mayor intimidad entre los participantes, una alta emocionalidad, estructura de diálogo y espontaneidad (Koch y Oesterreicher). Gracias a estos rasgos, es usual que "no siempre se acierta con lo que se quiere decir, o no se dice todo, confiando en que el interlocutor suplirá lo que falta. Resulta así un discurso impreciso, imprecisión que muchas veces es intencional, estratégica" (Acín 139). En La aproximación, Fuentes señala que estas imprecisiones pueden ser: (i) conscientes, cuando el hablante tiene algún motivo para no emplear el término adecuado, o (ii) inconscientes, cuando el hablante no conoce o no recuerda el término y elige otro parecido o cercano. De tal forma, los hablantes recurren a lo que Fant ha llamado modalización del acierto formulativo, un recurso que sirve "para compensar o neutralizar una imprecisión que se percibe en tal contexto como intencional" (45). Por todas estas características, la falta de precisión se ha relacionado con el lenguaje vago (Channell; Cutting) o con la expresión de sentido por aproximación (Vigara, Español), y varios autores coinciden en señalar que este es un fenómeno típico del discurso oral coloquial (Acín; Arias; Domínguez; Fuentes, La aproximación).

En términos generales, el lenguaje vago se refiere a ciertos mecanismos lingüísticos que son: "inherently and intentionally imprecise, describing lexical and grammatical surface features themselves that may refer either to specific entities or nothing in particular" (Cutting 4). Por su carácter intencional, el lenguaje vago no debe considerarse simplemente como la manifestación de una falta de pericia del hablante; más bien, es una estrategia que "modifies a linguistics item, phrase or utterance to make its meaning less precise" (Drave 25), por lo que se requiere "de la colaboración del interlocutor para precisarl[o]" (Domínguez 15). De esta manera, su empleo es el reflejo de una estrategia retórica de cortesía lingüística (Fuentes, La aproximación; Vigara, Español).

Por su parte, Vigara explica que la expresión del sentido por aproximación consiste en "procedimientos que nos permiten expresar algo más, algo distinto o algo que 'no es exactamente eso', sino 'oscuramente esto otro' en la lengua coloquial” (Español 25), y que lo importante es que, a pesar de la imprecisión, los hablantes son capaces de reconocer aquello que se quiere decir de manera casi inmediata, gracias al conocimiento compartido entre los interlocutores y a la inmediatez que supone el intercambio cara a cara. Así, este recurso es un reflejo de que en la interacción comunicativa "se concede prioridad a la 
transmisión 'fluida' de la información, y no importa tanto 'lo que dice el hablante' ni 'cómo lo dice', cuanto que se entienda perfectamente lo que se quiere decir" (Vigara, Español 16). Puesto en otras palabras, durante la conversación, los hablantes buscan alcanzar un intercambio comunicativo exitoso y -en aras de conseguirlo- pueden, incluso, emplear formas lingüísticas poco adecuadas o imprecisas que, no obstante, contribuyen a lograr un intercambio eficaz.

Ahora bien, existen diversos medios formales para codificar vaguedad, sufijos, adverbios, frases, sustantivos genéricos (Cutting; Fernández; Fuentes, La aproximación; Vigara, Morfosintaxis), expresiones lexicalizadas (Acín; Aliaga e Iglesias; Vigara, Morfosintaxis) y ciertos marcadores discursivos (Domínguez; Fuentes, La aproximación; González y Loureda; Loureda; Vigara, Español; autor). Todos estos medios ayudan a presentar la "información como no exacta, pero cercana a la verdad [...] revelan un modo de hablar voluntariamente impreciso" (Fuentes, La aproximación 226). En cuanto a sus funciones, se ha destacado que el lenguaje vago o por aproximación se emplea para evitar ser ofensivos, despectivos o pretenciosos, retener información, evitar mostrar falta de certeza o pobreza léxica y crear una adhesión a un grupo social particular (Channell; Cutting; Fernández y Yuldashev). De la misma forma, es un nivelador social que "puts the speakers on an immediately casual and equal footing with their interlocutors" (Alkhatnai 123), por lo que permite estrechar y reforzar las relaciones sociales entre ellos, gracias a la solidaridad que se genera a partir de la asunción de un conocimiento común. Nuevamente, esto permite atestiguar su papel como estrategia retórica de cortesía y atenuación (Fuentes, La aproximación; Vigara, Español).

Así pues, los hablantes pueden tener varias razones para recurrir al lenguaje vago, de manera que el uso de estos mecanismos no puede asociarse únicamente con una falta de destreza debido a algún olvido momentáneo o desconocimiento. En lo que sigue, nos detendremos a describir la relación entre expresiones lexicalizadas y marcadores discursivos como medios para la codificación de aproximación o vaguedad.

\subsection{Expresiones lexicalizadas y marcadores discursivos}

De acuerdo con Arribas, dentro de los estudios de los marcadores discursivos, un área poco explorada ha sido el análisis de unidades fraseológicas, "es decir, formas que, 
además del rasgo de fijación y de tener funciones procesuales, presentan carácter idiomático entendiendo por tal la ausencia de composicionalidad semántica” (66). Este tipo de unidades son parte de los pre-textos cliché: expresiones que pueden estar "fijas, memorizadas, que brotan de una sola vez en la mente del hablante y son interpretadas en bloque por su interlocutor" (Vigara, Pre-texto 267). Por su naturaleza, estas unidades han experimentado o están experimentando una fijación estructural en diferentes grados, por lo que pueden ser empleadas y comprendidas sin demasiados problemas por los interlocutores y esto contribuiría al desarrollo de sus funciones como marcadores del discurso.

En este contexto, en los últimos años, han surgido estudios interesados en analizar las propiedades discursivas de algunas de estas unidades; en particular, nos referimos a los casos de que (si) patatín que (si) patatán y que esto (y) que lo otro (Arias; Aliaga e Iglesias; González y Loureda; Loureda). En principio, se ha señalado que ambas formas están pasando por un proceso de lexicalización, de modo que aún se presenta cierta variación en su estructura; no obstante, pueden desempeñar funciones como marcadores discursivos (Arias; González y Loureda; Loureda; Pérez). Así, estructuralmente se ha puntualizado que que (si) patatín que (si) patatán tiene un alto grado de fijación, mientras que los constituyentes de que esto (y) que lo otro varían en un mayor grado. Por último, como suele suceder en estos casos, una forma de explicar a detalle los rasgos formales y funcionales de estas unidades es analizando sus elementos constituyentes: las conjunciones que y si y los verba omnibus, ya que están en la base de sus propiedades funcionales.

En principio, el que átono que encabeza a estas frases se ha descrito en función de un verbo dicendi explícito o implícito (Pons), especialmente en el caso del llamado que narrativo (Cascón; Pons; Porroche). Este que narrativo se ha asociado con dos funciones principales: (i) introducir otra voz y, al mismo tiempo, (ii) señalar el alejamiento del hablante con respecto a lo dicho por esa otra voz (Pons; Porroche). En el primer caso, es una marca de heteroglosia y cumple con funciones enunciativas, equivalentes a "alguien dice que" (González y Loureda; Porroche). En el segundo caso, que es una muestra clara de la presencia del hablante en la enunciación (Porroche), esto es, "la reproducción del discurso no solamente no es una mera repetición de las condiciones enunciativas del discurso original y de sus contenidos sino que supone manipularlos" (Aliaga e Iglesias 64) y adoptar una actitud particular ante ellos. Finalmente, este que no se limita simplemente a 
introducir un discurso ajeno, sino que, además, "Se trata de un procedimiento que consiste en mezclar el discurso directo con el indirecto, 'logrando conservar los elementos afectivos de los discursos relatados y desintelectualizar así el indirecto, de modo que mediante este que [narrativo] se puede desarrollar la actitud irónica satírica del narrador'” (Porroche 102103).

Por su parte, la locución que si ha sido analizada en función de su aparición en secuencias del tipo que (si)... que (si)..., que sirven para: (i) introducir otra voz, (ii) enumerar y (iii) cerrar series. La primera función, como se acaba de establecer, se atribuye a la presencia de que, ya que en estos casos se puede prescindir de $s i$, pero no de que -que patatín que patatán, pero no si patatín si patatán-(Aliaga e Iglesias; Pons; Porroche). De nueva cuenta, cuando el hablante emplea que si para reproducir el discurso ajeno, muestra su distanciamiento ante lo dicho y los segmentos que introduce "sirven de testimonio, no fiel, pero sí 'verosímil', de la existencia de la referencia al discurso ajeno al mismo tiempo que justifican la actitud evaluativa, explícita o implícitamente comunicada, que ha adoptado el hablante" (Aliga e Iglesias 66).

Ahora, en cuanto a la enumeración, Loureda la define como la expresión sucesiva, lineal o jerárquica de las partes de un todo, de manera que trasciende los límites de la oración, ya que se establecen dos tipos de relaciones, una entre las partes y otra entre las partes y un todo. Así, esta función se ha asociado con el carácter multimembre de la secuencia que (si)... que (si)..., que presenta los miembros que introduce como fragmentos de un tema más general, previamente señalado, y que requiere ser especificado (Aliaga e Iglesias; Arias). En este sentido, algunos autores destacan que los segmentos enumerados por que (si)... que (si)... suelen ser determinados (específicos) (Arias; Loureda), aunque también existen casos en los que son indeterminados (inespecíficos), particularmente cuando incluyen un verba omnibus. En cualquier caso, estas secuencias trabajan en el plano de la conexión, que "se efectúa en el nivel discursivo, apoyada tanto en marcas formales -la propia secuencia que si-, como en marcas prosódicas y en el contenido de la cita" (Aliaga e Iglesias 63). De tal forma, la conexión se establece a través de relaciones discursivas de cohesión, más que en relaciones netamente sintácticas (Aliga e Iglesias).

Finalmente, la función de cierre de serie se encuentra estrechamente ligada a la enumeración, ya que una secuencia que (si)... que (si)... puede ocurrir después de uno o dos 
elementos para señalar la conclusión de la enumeración (Acín). En otras ocasiones, cuando el hablante no recuerda un elemento o no sabe cómo continuar con la enumeración, recurre a estas secuencias, pero incluyendo un verba omnibus, para cerrar de manera indeterminada la serie (Loureda; Martín). En este sentido, las secuencias indeterminadas son estrategias de expresión de sentido por aproximación, ya que "el hablante reproductor indica claramente que no pretende hacer una reproducción ni de re ni, por supuesto, de dicto; es más, ni siquiera se toma la molestia de simular que se está siendo fiel, que se esté mimetizando el discurso ajeno" (Aliga e Iglesias 65). Para resumir, que si indica "procedimientos particulares para enumeración genérica (de cualquier cosa) y procedimientos para referirse a lo dicho por alguien (i.e. procedimientos metadiscursivos)" (Loureda 327). Estos dos procedimientos subrayan la actitud de alejamiento del hablante ante lo dicho, ya que "Presentar el discurso ajeno bajo la forma de una sarta devalúa la relevancia de cada una de las citas y parece más bien dirigido a socavar la imagen del enunciador original y de su discurso" (Aliga e Iglesias 65).

En cuanto a los verba omnibus, por su carácter indeterminado, sirven como "comodines", a través de los cuales el hablante puede referirse prácticamente a cualquiera cosa o acción, dejando indeterminada la referencia o apuntando a ningún referente en particular. Por esta razón, ocurren frecuentemente dentro de enumeraciones o listados, como en (3) y (4):

(3) 317 I: yo por eso/ a todo $<$ le $>$ tiro/ y le pruebo y veo para/ no tenerle miedo/ y eso me ayuda/ para aplicarlo con mis hijos/ ¿no?/ el día el momento que// yo/ yo estoy consciente que algún día mi hijo/ inclusive/ se va a emborrachar/ se vaya hasta drogar ¿no?/ y yo ya tengo el conocimiento de cómo guiarlo/ decirle/ "hijo esto es malo/ esto esto/ esto"/ "¿por qué?"/ "porque esto y por esto"/ o sea/ ¿sí me entiendes? (CSCM, entrevista 51).

(4) 221 I: entonces < entós:>// es cuando uno está niño/ ¡uh!/ se te hace mucho/ bastante dinero/ ¿no?/ "yo me voy a comprar esto/ me voy a comprar lo otro/ y para < pa> la otra le echo más ganas/ porque quiero comprarme esto otro" y así (CSCM, entrevista 37)

Como se puede apreciar, a pesar de no estar dentro de una forma lexicalizada, esto y lo otro enlistan elementos de manera indeterminada, por lo que su integración en la unidad 
que esto (y) que lo otro refuerza, automatiza y facilita esta interpretación, así como las demás funciones que codifica como marcador discursivo, como veremos a continuación.

\section{2 que esto (y) que lo otro y sus funciones discursivas}

La secuencia que esto (y) que lo otro es una forma cuasi-lexicalizada porque aún presenta variación en sus constituyentes; no obstante, hay una base que se mantiene casi constante, que esto (y) que lo otro (tuvo un índice del 83.3\% en nuestros datos). Pero, más allá de la alternancia, lo que hay que destacar es que todos los casos codifican las mismas funciones, de manera que esta forma ha desarrollado valores particulares como marcador discursivo (González y Loureda; Loureda). Desde una perspectiva categorial, coincide con la definición de operador, es decir, un estructurador "de la información con dos funciones primordiales: en primer lugar, indican el lugar que ocupa un miembro del discurso en el conjunto de una secuencia discursiva ordenada por partes; $y$, en segundo lugar, presentan el conjunto de esta secuencia como un único comentario y cada parte como un subcomentario" (Portolés 138). En este mismo sentido, Loureda señala que es un marcador con una estructura bimembre, que representa a dos elementos de un listado, de modo que su función primigenia -y que está siempre presente- es la enumeración.

Por su carácter indeterminado, el marcador tiene una acentuada tendencia a aparecer a final de lista o enumeración. En esta posición, refiere a elementos que cierran la serie, pero lo hace de tal forma que "nombran o aluden a cosas que no se quieren individualizar, por lo que pueden ser sustituidas por etcétera" (Loureda 329). Gracias a esta tendencia, se ha señalado que que esto (y) que lo otro ha desarrollado funciones de cierre de serie. Sin embargo, también es posible encontrar casos donde no cierra series, sino que aparece en posición intermedia de una serie que continúa. Tampoco es extraño que "la enumeración se compendia tras el primer enunciado en un recapitulador, o bien se impone una interpretación de enunciado suspendido" (Aliaga e Iglesias 55). En cualquiera de estos casos, el marcador "actúa como un difusor significativo, que deja los límites borrosos, como sin acabar, y esto hace que el significado de lo dicho sea impreciso" (Acín 144). Como ya se mencionó, esta referencia difusa obliga al oyente a reconstruirla, a partir de un proceso de inferencia donde el contexto desempeña un papel determinante. De esta forma, el oyente es quien interpreta y recupera (infiere) la referencia intentada por el hablante, 
quien deja "al buen entender del receptor la información sólo insinuada" (Vigara, Español $31)$.

Otra función más, asociada con la enumeración y la indeterminación, es la reproducción bosquejada de lo dicho por alguien más (González y Loureda; Loureda). En estos casos, el marcador alude "por lo general, a una serie de cosas o argumentos dichos por otros que no se quiere o no se puede concretar" (Loureda 339); así pues, el marcador sustituye fragmentos del discurso de alguien más "para obligar así a su interlocutor a rescatar las implicaturas contextuales no explicitadas en la cita y resultar así un enunciado de mayor carga informativa" (Arribas 81). Por lo regular, esta función se presenta en contextos de discurso indirecto mimético (Maldonado), donde el hablante puede señalar ostensivamente que los fragmentos sustituidos tienen un carácter repetitivo (Martí), que carecen de importancia o que simplemente se resume la mención literal original (Cascón); de tal forma, ha bastado con presentar solo un fragmento del habla reportada para que el interlocutor sea capaz de interpretar el contenido omitido y, más importante aún, para que identifique cuál es la actitud del hablante ante lo dicho por ese alguien más.

Ahora, debido a que este marcador se caracteriza por su indeterminación, es posible asociarlo con los mecanismos que expresan aproximación y que funcionan como difusores de significado o referencia. Es parte, pues, de las llamadas fórmulas inespecificativas que contribuyen a "difuminar esa información cuyos contornos o conexiones ni siquiera él mismo, como hablante y responsable de la comunicación, percibe muchas veces con nitidez" (Vigara, Español 31). En específico, aquí queremos señalar dos casos particulares: cuando el marcador actúa como marca de final de serie (Cortés, Los elementos. Perspectiva interactiva; Los elementos. Perspectiva textual) y cuando sustituye fragmentos de habla reportada, indicando que la información elidida carece de interés (Fernández; autor) o que se "duda de la veracidad de esa información o que no [se] está de acuerdo con esa opinión" (Orozco). En este último caso, además, es una forma de socavar la imagen del enunciador original (Aliaga e Iglesias). Finalmente, existen otros ejemplos donde el marcador, como fórmula inespecificativa, permite condensar información (Cortés, Los elementos. Perspectiva interactiva; Los elementos. Perspectiva textual) y evitar decir algo que pudiera considerarse como ofensivo. 
Así pues, que esto (y) que lo otro puede codificar alguno de estos valores gracias a su carácter indeterminado. Todas estas funciones confirman que, en la conversación coloquial, "a los interlocutores les interesa sobre todo, más que exactamente lo que se dice o cómo se dice, la participación personal activa en la comunicación y que se entienda 'aproximadamente' lo que se quiere decir; como ambos comparten el contexto y las expectativas de la comunicación, no suelen surgir obstáculos para la comprensión mutua" (Vigara, Morfosintaxis 270).

En resumen, hemos visto que las funciones de que esto (y) que lo otro son: (i) enumerar de forma indeterminada elementos de una lista, (ii) cerrar series, (iii) sustituir fragmentos de habla reportada y (iv) como mecanismo de aproximación. De tal forma, en $\S 4$, se analizarán estos usos en los datos del español de la Ciudad de México. Mientras tanto, en el siguiente apartado, se detalla la metodología que se siguió para la conformación del corpus y la manera en que se llevará a cabo el análisis.

\section{Metodología}

Debido a que el objetivo de nuestra investigación es caracterizar las funciones discursivas de que esto (y) que lo otro en el español de la Ciudad de México, era indispensable contar con tantos ejemplos como fuera posible. Por esta razón, se adoptó una metodología basada en el análisis de corpus, la cual permite acceder a un amplio número de datos, con la ventaja de que provienen de contextos naturales o menos controlados (Bolaños; Rojo). Esto último, además, es una condición sine qua non en el caso de estudios de corte pragmático y/o discursivo. Así pues, la lingüística de corpus resulta el "marco óptimo para el estudio de aquellos efectos pragmáticos que surgen por motivos intencionales, situacionales y sociológicos" (Albelda y Mihatsch 11), como ocurre en el caso de que esto (y) que lo otro.

\subsection{Corpus}

Este estudio incluye tres corpus pertenecientes a la variante del español de la Ciudad de México: (i) El habla de la ciudad de México. Materiales para su estudio (Lope Blanch), (ii) El habla popular de la ciudad de México. Materiales para su estudio (Lope Blanch) y 
(iii) Corpus Sociolingüístico de la Ciudad de México (Martín Butragueño y Lastra). E1 primero se compone de 32 entrevistas semi-informales y formales que corresponden a la norma culta; el segundo está compuesto por 34 entrevistas semi-informales e informales y corresponden al habla popular, y el tercero se compone de 108 entrevistas semi-informales e informales y está dividido en tres niveles de instrucción, alto (36), medio (36) y bajo (36). De esta manera, el corpus analizado en esta investigación asciende a 174 entrevistas.

En este escenario, gracias a que las entrevistas, en su mayoría, pertenecen al ámbito de lo informal, consideramos que son un marco propicio para la aparición del marcador que esto (y) que lo otro. Además, debido a las características de los corpus, los casos que se encuentren podrán ser analizados en contextos comunicativos más amplios, lo que resulta fundamental para la descripción de sus funciones discursivas. Por último, para la inclusión de los ejemplos en el texto, se decidió presentarlos respetando las convenciones de transcripción y etiquetado original de cada corpus y, en cada caso, se indica el material de procedencia y el número de estrevista o muestra al que pertenece.

\subsection{Procedimiento}

Por su objetivo, este estudio tiene un carácter cualitativo, que requiere del análisis detallado de cada ocurrencia de que esto (y) que lo otro, atendiendo principalmente a los contextos en los que aparece y a las funciones que codifica. Así, siguiendo estas condiciones, el primer paso fue revisar cada corpus de manera individual y manual para rastrear todas las ocurrencias de esto y otro cuando, en conjunto, formaban parte de una construcción cuasi-lexicalizada y cumplían funciones discursivas, más que sintácticas o semánticas. A partir de esta primera revisión, se excluyeron casos en donde esto y otro no ocurrían juntos, como en (5), y en donde su empleo no se ajustaba a las características formales señaladas en $\S 2.2$, como en (6).

(5) [hablando sobre una fiesta]

Inf.- Correcto; pero llegaron los señores. Pues que "un jaibolito". “¡Cómo no!” Eso sí se entendía muy fácilmente. El jaibolito, que el coñaquito, que la cena, que esto, que vamos a ver qué... a ver... ¿cómo se llaman?- langostinos (Norma culta, muestra VI). 
(6) 355 I: que "¡ay!/ qué me va a pasar"/ que "ay/ que esto"/ que "ay/ que lo otro"/ entonces pues// la primera vez sí te da miedo/ pero pues ya después/ las otras veces/ no/ pues ya sentiste lo que se [siente] (CSCM, entrevista 44).

Una vez que se descartó este tipo de ejemplos, el siguiente paso fue agrupar todas las formas que sí cumplían las condiciones formales y funcionales ya descritas. De esta manera, se encontró que las formas más comunes eran: que esto y que lo otro (20\%), que esto que lo otro (30\%), y que esto y que lo otro (16.7\%) y que esto y que el otro (10\%); en consecuencia, se plantea que la forma básica del marcador es: que esto (y) que lo otro. Es importante reiterar que se incluyeron todas estas formas porque, a pesar de la variación, desempeñan las funciones de enumeración, cierre de serie, sustitución de fragmentos de habla reportada y aproximación.

Posteriormente, después de que se identificaron todos estos casos, se procedió a analizar los contextos de ocurrencia, prestando especial atención a: (i) la relación que el marcador establece con los otros elementos de la enumeración, (ii) si el marcador se presentaba o no en contexto de habla reportada y (iii) si estaba en posición final de serie o no. En el primer caso, se encontró que, cuando el marcador era parte de una enumeración y no se encontraba en contexto de habla reportada, siempre aparecía, al menos, un miembro explícito del conjunto que se enumera. En el segundo caso, se comprobó que el habla reportada favorece su aparición, pues ocurrió en estos contextos en el 70\% de las ocasiones; además, en estos fragmentos, era posible que el marcador ocurriera sin la presencia de ningún elemento explícito del conjunto que se enumera. Finalmente, en el último caso, se concluyó que la posición preferida del marcador es a final de serie enumerativa, ya que apareció en este lugar el $80 \%$ de las veces, lo que permite confirmar su función como marcador de cierre de serie.

Así pues, a partir de estos primeros resultados, el último paso fue llevar a cabo el análisis de las funciones de que esto (y) que lo otro, análisis que se presenta a detalle en el siguiente apartado. 


\section{Análisis}

Como se explicó antes, la enumeración supone, por un lado, la presencia de un conjunto o una categoría general y, por el otro, la de una serie de elementos que pertenecen a ese conjunto o a esa categoría general. De tal forma, los elementos individuales están subordinados a la categoría general y, al mismo tiempo, guardan una relación de coordinación entre ellos. En este sentido, que esto (y) que lo otro refiere, de manera indeterminada, a dos elementos de la serie, que pertenecen a un mismo grupo o categoría. Por su carácter inespecífico, el marcador suele aparecer después de uno o dos elementos explícitos para que el interlocutor sea capaz de inferir lo sugerido por el marcador, como un mecanismo de aproximación:

(7) Inf. B.- No le quedaba nada más que relegarse a su casa y esperar unos cinco, diez años, entre... añoranzas de que si la visitan los hijos, que si no la visitan, que si llena de sentimientos, que esto, que lo otro... Eso ya pasó a la historia (Habla popular, muestra XVII).

(8) 655 I: mucho muy bonito y ahora que se alterna con/ que que/ que se vende pintura/ que agujetas $<\sim$ abujetas $>/$ que plantillas que esto que lo otro $<\sim$ lotro $>$ / antes no/ antes nada más era reparador de calzado y maquila y y se acabó/ no había otra cosa (CSCM, entrevista 98).

(9) 415 I: [ajá]/ pues fijate que/ yo a/ bueno mi hijo $<\sim$ mijo $>$ ahorita $<\sim$ orita $>$ / antes se dejaba abrazar < abraza:r> se dejaba que lo apapacharan/ ahora ya no/ ahora se la pasa por ejemplo como mi esposo descansa los lunes/ se la pasa con mi esposo/ "no vente que vamos a hacerle esto al carro que esto y que lo otro"/ se va con su papá (CSCM, entrevista 96).

En (7), la serie consta de tres segmentos explícitos, que si la visitan los hijos, que si no la visitan, que si llena de sentimientos, y que esto que lo otro son dos segmentos más de dicha serie, pero no se encuentran especificados; no obstante, el interlocutor puede inferir que se relacionan con la categoría añoranzas, que es a la que pertenecen todos los demás elementos. Por su parte, en (8), el hablante enumera explícitamente tres productos que ahora se venden en las reparadoras de calzado: pintura, agujetas y plantillas, y que esto que lo otro hace referencia a otros productos más, pero de manera indeterminada. Por último, en (9), dentro de un segmento de habla reportada, la hablante sustituye partes de la cita con 
que esto y que lo otro, que hacen referencia a otras actividades que el padre le propone al hijo. En este ejemplo, lo que se enumera son fragmentos de habla reportada, uno de manera específica y dos de forma indeterminada.

Cabe destacar que, en nuestro datos, en todos los casos de enumeración de elementos, como (7) y (8), estaba presente, al menos, un elemento explícito, pero en casos como (9) no era necesario, de manera que hay ejemplos donde aparece únicamente el verbo dicendi seguido del marcador:

(10) 140 I: y ni a él ni a mí nos gustan pero yo sí es muy/ es más fácil que yo me moleste// que él/ o sea él/ no le da importancia y se acabó// y a mí me costaba trabajo// yo no/ o sea/ yo lo escuchaba y decía/ "ah/ le voy a decir que esto [que] lo otro"/ no sé// pero no tiene caso// no tiene caso/ entonces dije "voy a actuar más inteligente" (CSCM, entrevista 9).

Ahora bien, gracias a su uso dentro de listados y a su carácter inespecífico, que esto (y) que lo otro tiende a ocurrir como elemento final de enumeración, por lo que se le ha asociado con una función de cierre de serie, como en (11) y (12). No obstante, y aunque de manera menos frecuente, también puede suceder que este elemento aparezca en posición intermedia de una serie que continúa, como en (13) y (14):

(11) [Hablando sobre adicciones] Inf.- No; yo de eso, no. No, nada de eso. Sí me gusta a mí... mi... a ver... Güeno, desde jovencito me... mi pulque y o eso, ¿no?, pero... pero entóns en esa época, no se... no se acostumbraba todo eso.

Enc.- Sí. Ora hay que...

Inf.- Que cemento, que esto, que l'otro. Y hasta la fecha, ¿no? a le digo, ¿no? Aquí me tiene, ¿no? como responsable de... de mi hogar (Habla popular, muestra X).

(12) 90 I: al mostrarme como persona y compartir mi experiencia/// con las demás este mujeres/ eh/ han permitido más/ les he les he aportado algo más/// que que por ejemplo ellas me fueran a ver como terapeuta/// y de repente empezamos/ "iah!/ que los niños/ que esto y que el otro"/ y terminamos reflexionando/ ¿no?/ y "¡ah!/ oye/ de veras"/ ¿no? (CSCM, entrevista 22).

(13) 178 I: y este/ y éramos puras mujeres/ puras mujeres/ nada más como tres hombres/ y ya empecé yo a hacerme/ ya sabes amiga de todas/ $y$ que esto y que lo otro y que "vamos a un baile"/ "pues órale"/ y a ella 
le gustaba también mucho ir al baile/ y ya de ahí empezamos (CSCM, entrevista 57).

(14) 1034 I: “¿cómo estás hija?/ que esto/ que lo otro/ y ¿cómo está el clima? ¿cómo has estado?"/ entonces/ hablamos más bien de eso/ pero realmente no hablamos de $<\sim$ de: $>/$ cómo se llama el restorán y/ “¿dón- en qué colonia vives? (CSCM, entrevista 64).

En (11), el hablante enlista una serie de productos nocivos, pero solo presenta uno explícitamente, cemento, y con que esto que lo otro cierra, de forma indeterminada, la enumeración de elementos, aunque el interlocutor puede inferir fácilmente a qué tipo de productos se está refiriendo el hablante. En (12) sucede algo parecido, la hablante enlista los temas que trata con las demás mujeres y solo presenta uno explícitamente, los niños, y con que esto y que el otro cierra el listado. En ambos casos, la presencia del único elemento explícito permite que el interlocutor infiera, de manera aproximada, a qué elementos apunta el marcador.

Por su parte, en (13) el marcador ocurre en medio del listado, el primer elemento es y ya empecé yo a hacerme ya sabes amiga de todas, después aparece y que esto y que lo otro y le sigue y que "vamos a un baile"; de tal forma, el marcador está relacionado, de manera indeterminada, con el primer elemento, mientras que el último es una individualización del primero. En cuanto a (14), el marcador también se encuentra en posición intermedia de serie, le antecede un elemento determinado, ¿cómo estás hija?, y le siguen dos elementos determinados más ¿cómo está el clima? y ¿cómo has estado?. Así pues, en (13) y (14), que esto (y) que lo otro no cierra series, solo enumera elementos indeterminados. Con todo, en nuestros datos fue mucho más frecuente que el marcador se encontrara en posición final de serie $-80 \%$ de las veces-, que en posición inicial o intermedia, por lo que su función de cierre de serie quedó bastante bien atestiguada.

Por otro parte, también se ha destacado la tendencia que tiene que esto (y) que lo otro para aparecer dentro de segmentos de habla reportada, regularmente lo que hace es sustituir fragmentos de la cita, ya sea porque el hablante considera que el contenido carece de relevancia o porque no comparte la opinión del enunciador original y trata de restarle importancia y/o veracidad. Cabe señalar que el discurso referido puede corresponder a 
alguien más, como en los casos de (15) y (16), o al mismo hablante, como en (17), aunque esto último es menos habitual.

(15) 535 I: hemos llegado a discutir así fuerte/ que sí luego en un momento "ay no ya me voy a ir"/ o "ya lárgate ya me tienes harto" así/ pero al rato se le baja el coraje < cora:je $>$ y todo y ya/ "ay chaparra es que tú me haces que hable de más $<\sim$ má:s $>/$ es que esto $y$ que lo otro < otro:>"/ y ya/ le digo "no pero es que tú me gritaste y tú me dijiste" y ya/ "no es que mira tú ponte en mi lugar tú me dijiste esto" (CSCM, entrevista 96).

(16) 146 I: y yo le dije [practico] que el box/ y la natación/ y le hace "ay $<\sim a: i>$ no sí estás bien piernudo" y que me agarra la pierna y le digo "no ¿sabes qué?" que me orillo y que le digo "bájate/ bájate" "ay no que quién sabe qué que llévame que esto que lo otro"/ le digo "no $<\sim$ no: $>$ si te ves bien hombrecito como para que me andes manoseando" (CSCM, entrevista 74).

(17) 456 Q: yo/ le dije/ si por eso yo le he estado insistiendo porque/ "no/

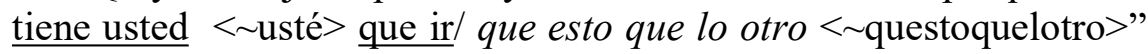
(golpe fuerte)

457 E: pero ¿para < pa> qué te enojas? (CSCM, entrevista 64).

En los tres casos, el marcador sustituye fragmentos de habla reportada, pero sigue conservando las funciones antes señaladas, enumera una lista de elementos y aparece cerrando una serie de forma indeterminada. Además, los tres ejemplos incluyen un segmento explícito -tú me haces que hable de más, que llévame y no tiene usted que irque permiten inferir el contenido de los fragmentos sustituidos. Por otro lado, hay que señalar que el marcador también puede aparecer en contextos fuera de cita, como en (18) y (19), pero son casos muy poco frecuentes. En particular, en nuestros datos, que esto (y) que lo otro ocurrió $70 \%$ de las veces en contexto de habla reportada; de tal forma, se puede confirmar la tendencia de este marcador a sustituir fragmentos de discurso referido, tal y como se ha reportado en otros estudios (Loureda; González y Loureda).

(18) 497 I: y este/ pues lo conocía a él/ por/ por su hermano/ que luego/ y/ decía/ "vente/ acompáñame a ver a mi mamá"/ y ya la íbamos a ver/ y ya me estaba ahí/ ya después él me empezó a hablar y todo eso// entonces < tons> ya de ahí ya empezamos que/ que a salir/ y que esto y que lo otro/ empezamos/ entonces < tonces> pues/ ya// ya empezamos ahí a estar $<\ldots>$ (CSCM, entrevista 44). 
(19) Inf. - Luego ni... comer en la calle y...pue... est... Es una cosa que... ¿no?... es una cosa que... no, no se... no se puede soportar, ¿no? Y al menos uno, ¿no?... Ps ora hay familias que tienen ipero escalera de chiquillos! Ai'stá... tá (está) más duro, ¿no? Tá que cálzalos, que vestilos, que... que esto, que lo otro (Habla popular, muestra $\mathrm{X}$ ).

Así pues, hasta aquí hemos visto que el marcador siempre cumple con funciones de enumeración y lo hace de manera indeterminada, también se destacó que la segunda función más común es aparecer como cierre indeterminado de serie y, por último, la tercera función es la de sustituir fragmentos de habla reportada. En los tres casos, la enumeración y la indeterminación están siempre presentes, por lo que son características ubicuas de este marcador, que ayudan a explicar su relación con la expresión de sentido por aproximación, como se detalla a continuación.

Ya se ha dicho que los mecanismos de aproximación son estrategias que permiten, entre otras cosas, cerrar series de manera indeterminada, señalar el carácter irrelevante de una información, abreviar contenido y evitar decir algo que pueda resultar ofensivo. Creemos que los dos primeros casos han quedado bastante bien ilustrados a lo largo de los ejemplos presentados, por lo que no agregaremos nada más. En el caso de la abreviación de la información, el marcador se emplea para concluir una serie cuando el hablante busca "no elaborar innecesariamente el discurso o no querer ser demasiado explícito" (Cortés, Los elementos. Perspectiva textual 71) o cuando "El hablante termina el discurso porque considera innecesario seguir precisando términos" (Fuentes, Diccionario 349):

(20) 652 I: [pero fíjate] que este < este:>/ H no tanto/ $\mathrm{H}$ se va mucho por// la < la: $>/$ dice él "disciplina de escena"/ que sean líneas/ que sean cuadros/ que sean cruces/ que sean/ que el paso/ que todos parejos/ que esto/ y que lo otro/ entonces < tonces> es lo que me gusta de él (CSCM, entrevista 42).

En (20), I individualiza varios elementos relacionados con disciplina en escena. Después de presentar cinco de ellos, concluye la enumeración porque considera que ya ha sido prolija y, a través del marcador, cierra la serie de forma indeterminada, al tiempo que señala que hay otros elementos que no serán especificados. En casos como este, el 
marcador es una de las estrategias que adoptan los hablantes para adherirse a la máxima de cantidad (Grice).

Por su parte, existen otros ejemplos en los que el hablante emplea este marcador para evitar decir palabras que puedan considerarse como ofensivas $\mathrm{y}$, de esta manera, salvaguarda su imagen ante el interlocutor, de manera que es parte de una estrategia de cortesía positiva:

(21) Inf. A.- "Mi coronel, o mi general: quiero irme a estudiar a la Escuela de Guerra" "Haga su solicitud". Entonces... claro, cuando ya llegó la solicitud por escrito: "Este no más tal por cual" "Que esto y [que] el otro"... no piensa, coge un cerillo y ipum!, la quema y ya (Habla culta, muestra XVI).

En (21), se está narrando que un mando militar se molestó con un subordinado por intentar estudiar en la Escuela de Guerra y se cita, a través de eufemismos, la forma en que el superior se refería al cadete: tal por cual, y que esto y [que] el otro hace referencia a otros calificativos que I prefiere omitir, pero que el interlocutor puede inferir fácilmente. Así pues, gracias a estas funciones, se puede comprobar que esto (y) que lo otro también cumple funciones relacionadas con el lenguaje vago o por aproximación.

Abreviando, hemos descrito que esto (y) que lo otro tiene tres funciones principales: (i) enumerar elementos indeterminados de una serie, (ii) cerrar series de manera indeterminada y (iii) sustituir fragmentos de habla reportada. Además, por su carácter siempre indeterminado, puede desempeñar otras funciones asociadas con la aproximación, en especial: marcar el final de una serie (Cortés, Los elementos. Perspectiva interactiva; Los elementos. Perspectiva textual), señalar el carácter irrelevante de cierto elemento o de una parte de lo dicho por alguien más (Fernández; autor), condensar información (Cortés, Los elementos. Perspectiva textual; Fuentes, Diccionario) y omitir información para salvaguardar la imagen propia. De esta manera, por su función como mecanismo de aproximación, a través de que esto (y) que lo otro:

el hablante pretende proporcionar y proporciona al receptor una determinada información-X, pero actúa subjetivamente sobre ella (unas veces intencional, otras inconscientemente) y la realiza verbalmente como $\mathrm{Y}$, que no expresa con exactitud $\mathrm{X}$, pese a lo cual la interpretación del 
receptor coincide con la pretendida por su interlocutor (Vigara, Español 28).

\section{Discusión}

Nuestro principal interés era describir las funciones de que esto (y) que lo otro y, posteriormente, relacionarlas con los valores de la aproximación. En particular, queríamos determinar si este marcador puede ser considerado como uno de los mecanismos que comunican por aproximación. Así pues, a partir del análisis de los datos, se concluyó que el marcador desempeña tres funciones particulares: (i) enumeración indeterminada, (ii) cierre indeterminado de serie y (iii) sustituto de fragmentos de habla reportada. En los tres casos, el marcador se caracteriza por su indeterminación, de manera que se puede asociar con el lenguaje vago y la aproximación.

En principio, hay que destacar que, gracias a la preferencia por aparecer a final de enumeración, esta partícula se comporta como una marca de final de serie (Cortés, Los elementos. Perspectiva interactiva; Los elementos. Perspectiva textual), esto es, que esto (y) que lo otro le indica al oyente que, como parte del listado, existen otros elementos de la serie que el hablante no quiere o no puede mencionar, de manera que el interlocutor debe inferir su referencia (Domínguez; autor), lo que resulta sencillo gracias al contexto discursivo previo, como en los ejemplos de (8) y (11). De esta manera, el marcador tiene valores de difusor de significado y de abreviación discursiva y, como se señaló, esta abreviación se puede presentar cuando el hablante trata de no elaborar más de la cuenta, como en (20), o cuando evita decir algo que lo pueda comprometer, como en (21).

Ahora bien, como el oyente es quien debe realizar "el esfuerzo de reconstruir la intención comunicativa del hablante" (Borreguero 55), la aparición de este marcador contribuye a generar una cercanía social, una especie de complicidad, ya que se involucra activamente al interlocutor para que infiera la referencia intentada por el hablante. Así pues, esta reconstrucción del sentido es “un proceso de ‘cálculo' y ‘negociación' de significados que tienen su origen en el emisor, pero sólo se realiza plenamente por la interpretación contextualizada del receptor" (Vigara, Español 16). De tal forma, como señalan Overstreet y Yule, hablante y oyente "construct meaning at the implicational level and create social 
closeness with their interlocutors without the risk of being misunderstood" (Cit. en Fernández 8). Por estas razones, se concluye que que esto (y) que lo otro es parte de una estrategia de cortesía positiva y, como tal, su empleo responde a una intención consciente del hablante por establecer una relación más estrecha con el oyente.

Por otro lado, cuando el marcador sustituye fragmentos de habla reportada también suele aparecer en posición final; de tal forma, el hablante cita uno o dos segmentos de manera explícita para que el interlocutor pueda inferir a qué está apuntando el marcador. En este sentido, ya se ha dicho que los marcadores de habla aproximada suelen ocurrir después de segmentos de habla reportada, con lo que indican el carácter intrascendente de la parte que se ha omitido (Fernández; autor). En estos casos, el marcador también desempeña funciones de abreviación discursiva, puesto que el hablante ha dado información suficiente para que el interlocutor se dé una idea general de lo que se ha querido comunicar. Ahora, también se puede eliminar una parte del habla reportada para señalar otras actitudes del hablante con respecto a la cita; en particular, al presentar de forma bosquejada lo dicho por alguien más, el hablante se aleja del contenido citado, ya sea porque carece de veracidad o porque no se está de acuerdo con la opinión; al hacerlo así, se desacredita la figura del enunciador original. De tal forma, estos usos están relacionados con una función de atenuación asertiva (Fuentes, La aproximación). En breve, el marcador es una muestra clara de la presencia del hablante y de su actitud frente a la información contenida en el habla reportada. Como se mencionó antes, esto se debe a la presencia de que y su origen con funciones narrativas (Cascón; Pons; Porroche).

En resumen, que esto (y) que lo otro no solo cumple funciones discursivas específicas, sino que, además, se relaciona con valores más generales de la expresión de sentido por aproximación. Como se ha visto, permite condensar el discurso y omitir información que pudiera considerarse superflua; cierra series al mismo tiempo que indica que hay más elementos que no se especificarán; en otros casos, se omite información porque puede ser considerada inapropiada u ofensiva y, de esta forma, se salvaguarda la imagen propia. Finalmente, se ha descrito que la aproximación es un mecanismo que contribuye al establecimiento de cortesía lingüística porque provoca la construcción de un significado intersubjetivo, con lo que se genera solidaridad entre los interlocutores (Chesire; Fernández y Yuldashev), a través de un proceso dialógico que "involve the 
Artículo. Josaphat Enrique Guillén Escamilla. "Las funciones discursivas de que esto (y) que lo otro y su valor indeterminado. Un estudio en datos del español de la Ciudad de México"

construction or assumption of common ground among interlocutors" (Fernández 5). Por todo esto, que esto (y) que lo otro es un marcador discursivo que codifica aproximación y, por tanto, comparte funciones con otros marcadores como: y así, y cosas así, y todo eso, o cosas así, y tal, etcétera. Por último, hay que resaltar que los hablantes emplean este marcador de manera intencional, por lo que su uso responde al seguimiento de estrategias discursivas y no es simplemente el reflejo de los problemas que puedan experimentar durante la formulación de su discurso.

\section{Conclusiones}

El objetivo de este trabajo era describir las funciones discursivas de que esto (y) que lo otro en el español de la Ciudad de México y, además, relacionarlas con los valores de indeterminación. En principio, se estableció que es un marcador que aún no se encuentra totalmente fijo, aunque sí hay una estructura básica, que esto (y) que lo otro. Luego, a partir del análisis de los datos, se corroboró la presencia de las tres funciones descritas en estudios previos: (i) enumeración indeterminada, (ii) cierre indeterminado de serie y (iii) sustituto de fragmento de habla reportada (Arias; Aliaga e Iglesias; González y Loureda; Loureda). En específico, se estableció que la enumeración y la indeterminación son rasgos que se encuentran siempre presentes en el marcador, por lo que pueden considerarse como la base de las funciones (ii) y (iii). Así, no en todos los casos el marcador ejerce como cierre indeterminado de serie, aunque sí hay una tendencia hacia esta función. De manera similar, el marcador tampoco se encontraba siempre en contexto de habla reportada, aunque también tuvo un índice alto de aparición en dicha circunstancia.

En cuanto a la relación de que esto (y) que lo otro con la aproximación, se destacó que, cuando funciona como cierre indeterminado de serie y como sustituto de habla reportada, codifica valores inespecificativos, estos es, permite comunicar "algo que "no es exactamente eso', sino 'oscuramente esto otro"' (Viagara, Español 25) y, a pesar de esta aparente impresición, los interlocutores se siguen entendiendo sin muchos problemas. Como es de esperarse, este valor proviene principalmente de los verba omnibus que componen al marcador y que le imprimen un carácter de difusor de significado. 
En breve, que esto (y) que lo otro, a pesar de no estar completamente fijado, puede considerarse como un marcador discursivo que tiene una función básica: enumerar elementos de una serie y lo hace de manera indeterminada. Asociado con lo anterior, también tiene una tendencia a cerrar series -el $80 \%$ de las veces en nuestros datos- y a aparecer como sustituto de fragmentos de habla reportada $-70 \%$ de las veces en nuestro datos-. Finalmente, se concluye que, debido a su carácter indeterminado, se puede considerar como parte de los mecanismos de aproximación o vaguedad. Por último, hay que señalar que este es un primer acercamiento al análisis de este marcador y su relación con la aproximación, de manera que serán necesarios más análisis de esta naturaleza; por ejemplo, centrados en estudiar con mayor detalle aquellos aspectos relacionados con cortesía y atenuación.

\section{REFERENCIAS}

Acín, Esperanza. "Yo qué sé, digamos, y tal: la imprecisión en el discurso oral informal". Pragmática y discurso oral, edición de Olga Ivanova, Carmen Álvarez y Manuel Nevot. Ediciones Universidad de Salamanca, 2020, pp. 139-152.

Albelda, Marta y Wiltrud Mihatsch. "Introducción". Atenuación e intensificación en géneros discursivos, edición de Marta Albelda y Wiltrud Mihatsch. Iberoamericana/Vervuert 2017, pp. 9-20.

Aliaga, Francisco y Silvia Iglesias. "Una construcción del español coloquial: que si patatín, que si patatán". Sintaxis y análisis del discurso hablado en español: homenaje a Antonio Narbona, coordinación de José de Bustos, Rafael Cano, Elena Méndez y Araceli López. Universidad de Sevilla, 2011, pp. 51-70.

Alkhatnai, Mubarak. "Vague Language and Its Social Role". Theory and Practice in Language Studies, vol. 7, núm. 2, 2017, pp. 122-127.

Arias, Elizabeth. “"...que si la comida y tal...': Un marcador enumerativo para la especificación de la referencia textual". Lengua y Habla, núm. 15, 2011, pp. 1-13.

Arribas, Nieves. "Donde había dicho, diría después Diego". Metalinguaggi e metatesti. Lingua, letteratura e traduzione, XXIV Congresso AISPI (Padova, 23-26 maggio 2007), edición de A. Cassol, A. Guarino, G. Mapelli, F. Matte y P. Taravacci. AISPI: Edizioni, 2012, pp. 65-91.

Bolaños, Sergio. "La lingüística de corpus: perspectivas para la investigación lingüística contemporánea". Forma y Función, 28.1, 2015, pp. 31-54.

Borreguero, Margarita. "Los marcadores de aproximación (en el lenguaje juvenil): esp. en plan vs. it. tipo". España e Italia: un viaje de ida y vuelta. Studia in honorem Manuel Carrera Díaz, coordinación de Miguel Cuevas, Fernando Molina y Paolo Silvestri. Editorial Universidad de Sevilla, 2020, pp. 53-78.

Briz, Antonio. El español coloquial. Situación y uso. Arco/Libros, 1996. 
---. “Los llamados 'cortes sintácticos' de la conversación coloquial”. Anuari de Filologia. Estudis de Lingüística, núm. 8, 2018, pp. 1-19.

Cascón, Eugenio. Español coloquial: rasgos, formas y fraseología de la lengua diaria. Edinumen, 2006.

Channell, Joanna. Vague Language. Oxford University Press, 1994.

Cheshire, Jenny. "Discourse variation, grammaticalisation and stuff like that". Journal of Sociolinguistics, 11.2, 2007, pp.155-193.

Cortés, Luis. "Los elementos de final de serie enumerativa del tipo y todo eso, o cosas así, y tal, etc. Perspectiva interactiva”. Boletín de lingüistica, núm. 26, 2006, pp. 102129.

---. $\quad$ "Los elementos de final de serie enumerativa del tipo y todo eso, o cosas así, y tal, etcétera en el discurso oral en español. Perspectiva textual". BISAL, núm. 1, 2006, pp. 55-80.

Cutting, Joan. "German, Spanish and Mandarin speakers' metapragmatic awareness of vague language compared". Journal of Pragmatics, núm. 151, 2019, pp. 128-140.

Drave, Neil. "Vaguely speaking: A corpus approach to vague language in intercultural conversations". Language and Computers, núm. 36, 2001, pp. 25-40.

Domínguez, Carmen. "Marcadores de (in)conclusión en el español hablado en MéridaVenezuela". Boletín de Lingüística, núm. 23, 2005, pp. 3-22.

Fant, Lars. "La modalización del acierto formulativo en español". RILI, vol. 5, núm. 1, pp. 39-58.

Fernández, Julieta. "General extender use in spoken Peninsular Spanish: metapragmatic awareness and pedagogical implications". Journal of Spanish Language Teaching, vol. 2, núm. 1, 2015, pp. 1-17.

Fernández, Julieta y Aziz Yuldashev. "Variation in the use of general extenders and stuff in instant messaging interactions". Journal of Pragmatics, núm. 43, 2011, pp. 26102626.

Fuentes, Catalina. "La aproximación enunciativa". Lingüística Española Actual, vol. 30, núm. 2, 2008, pp. 223-258.

---. Diccionario de conectores y operadores del español. Arcos, 2009.

Gille, Johan. “'Iraq, y cosas así': los apéndices conversacionales en español coloquial. Moderna Sprak, núm. 100, 2006, pp. 157-166.

Gille, Johan y Cilla Häggkvist. "Los niveles del diálogo y los apéndices conversacionales". Discurso, interacción e identidad, coordinación de Johan Falk, Johan Gillle y Fernando Wachtmeister. Universidad de Estocolmo, 2006, pp. 65-80.

González, Ramón y Óscar Loureda. "Algunos estudios recientes sobre lo metalingüístico en español”. Verba, núm. 32, 2005, pp. 351-369.

Grice, Paul. "Logic and conversation". Syntax and semantics. Volume 3. Speech Acts, edición de Peter Cole y Jerry Morgan. Academic Press, 1975, pp. 41-58.

Koch, Peter y Wulf Oesterreicher. Lengua hablada en la Romania: español, francés, italiano. Gredos, 2007.

Lope Blanch, Juan Manuel, coord. El habla de la ciudad de México: Materiales para su estudio. UNAM, 1971.

---. El habla popular de la ciudad de México. Materiales para su estudio. UNAM, 1976.

Loureda, Óscar. "Sobre un tipo de marcadores discursivos de enumeración en el español actual”. RILCE, vol. 16, núm. 2, 2000, pp. 325-342. 
Maldonado, Concepción. "Discurso directo y discurso indirecto". Gramática descriptiva de la lengua española V. 3, coordinación de Violeta Demonte e Ignacio Bosque. Espasa, 1999, pp. 3549-3596.

Martí, Manuel. "Los conectores discursivos (entre los otros marcadores discursivos y los otros conectores)". Lingüística en la red, núm. 9, 2011. http://www.linred.es/articulos_pdf/LR_articulo_30102011.pdf. Consultado el 19 de junio de 2021.

Martín Butragueño, Pedro y Yolanda Lastra, coords. Corpus sociolingüístico de la Ciudad de México. Vol. 1: Hablantes de instrucción alta. El Colegio de México, 2011.

---. Corpus sociolingüístico de la Ciudad de México. Vol. II: Hablantes de instrucción media. El Colegio de México, 2012.

---. Corpus sociolingüístico de la Ciudad de México. Vol. III: Hablantes de instrucción baja. El Colegio de México, 2015.

Narbona, Antonio y Ramón Morillo. Las Hablas andaluzas. Monte de Piedad y Caja de Ahorros de Córdoba, 1987.

Orozco, Leonor. "según”. Diccionario de partículas discursivas del español, coordicación de Antonio Briz, Salvador Pons y José Portolés. http://www.dpde.es/\#/entry/segun. Consultado el 14 de junio de 2021.

Pérez, Bernardo. "Funciones discursivas de esto, eso y aquello en un corpus oral". Anuario de Letras, vol. 2, núm. 1, 2014, pp. 103-140.

Pons, Salvador. "que inicial átono como marca de modalidad". ELUA, núm. 17, 2003, pp. 531-545.

Porroche, Margarita. "Algunos aspectos del uso de que en el español conversacional (que como introductor de oraciones 'independientes"'. CLAC, núm. 3, 2000, pp. 100116.

Portolés, José. Marcadores del discurso. Ariel, 1998.

Rojo, Guillermo. Introducción a la lingüística de corpus en español. Routledge, 2021.

Tusón, Amparo. Análisis de la conversación. Ariel, 1997.

Vigara, Ana María. Morfosintaxis del español coloquial. Gredos, 1992.

---. "Pre-texto y realización del sentido en el español coloquial". Paremia, núm. 2, 1993, pp. 267-275.

---. "Español coloquial: Expresión del sentido por aproximación”. El español hablando y la cultura oral en España e Hispanoamérica, coordinación de Thomas Kotschi, Wulf Oesterreicher y Klaus Zimmermann. Vervuert, 1996, pp. 15-44. 